\title{
NOTE ON THE BRAZILIAN FIRE-ANT, SOLENOPSIS SAEVISSIMA F. SMITH.
}

\section{By William Morton Wheeler.}

While discussing the various North American forms of Solenopsis geminata Fabr. in a recent paper ${ }^{1} \mathrm{I}$ stated that the ant described many years ago as Myrmica savissima by Frederick Smith from specimens taken by Bates at Pará, is, in all probability, identical with the one later called Solenopsis pylades by Forel. My reasons for making this statement were these: "In the first place, Smith's description is unusually good and applies perfectly to the typical yellow pylades. In the second place, his specimens were received from Bates, who gives an interesting account of the habits of this 'fire-ant' in Brazil. Moreover, Mr. W. M. Mann, who collected extensively in the region where Bates collected his specimens and made his observations, tells me that it is there the only common and widely distributed Solenopsis, and the numerous specimens collected by Mr. Mann prove to be the typical pylades Forel." Forel, however, will not assent to this opinion. ${ }^{2}$ He says that Smith mentions a worker major and a worker minor in his description, whereas it was precisely the feeble polymorphism of the worker that led to the separation of pylades from geminata. Surely Forel, who has had to spend so many precious hours in the interpretation of Smith's inadequate and faulty specific descriptions, ought not to regard his statements concerning major and minor workers as meaning anything more than a perceptible difference in size. My critic, however, completely ignores the second and third points of my contention, which to me seemed to be the more important.

In order to settle the matter, I sent several specimens of the typical yellow pylades Forel, taken by Dr. Mann at Pará, to my friend, Mr. Horace Dornisthorpe, with the request that he compare them with the types of Smith's sovissima in the British Museum. He writes me under date of July 3 as follows: “I compared

\footnotetext{
1 Some Additions to the North American Ant-Fauna. Bull. Amer. Mus. Nat. Hist., 34, 1915 , p. 395 .

2 Fourmis du Congo et d'autres provenances récoltées par MM. Hermann Kohl, Luja, Mayne, etc. Rev. Suisse Zool., 21, 1916, p. 459.
} 
the ants you sent me with F. Smith's types (two workers on one card, one large, one medium) of Solenopsis sovissima at the British Museum on Saturday and they agree perfectly in every way. The types were taken by H. W. Bates at Pará." There can be no doubt, therefore, that Forel's pylades is merely a synonym of savissima Smith.

Forel disagrees with me further on the rank of this form, maintaining that it should be regarded as a distinct species and not as a subspecies of geminata, because the polymorphism of the worker is very feeble, owing to the complete absence in the colonies of any large-headed forms like those of geminata. This is a matter of personal opinion. I called attention to the fact that two of our North American forms, maniosa Wheeler and xyloni MacCook are in this respect intermediate between sovissima and geminata, and I may add that the Brazilian form medusa, recently described by Mann, is even more polymorphic than geminata since its largest workers have the head greatly enlarged and flaring in front, with very strongly curved mandibles. If sovissima is elevated to specific rank, these forms should also have the same status, but in my opinion they may all be regarded as so many subspecies of a single variable species. I admit that it might be more logical to include aurea Wheeler as still another subspecies, with amblychila Wheeler as its variety. Owing to the great accumulation of forms in this section of the genus Solenopsis within recent years I am not altogether averse to regarding sovissima, geminata, maniosa xyloni, electra, medusa and aurea as so many different, though very closely allied, species.

\section{AN ANOMALOUS BLIND WORKER ANT.}

\section{By William Morton Wheeler.}

Several years ago Prof. C. F. Baker sent me from Catalina Island, Calif., a number of ants which I described as Aphonogaster patruelis Forel var. bakeri. Later he gave me a vial of additional specimens from the same colony. While mounting these I detected among them a single eyeless worker, which seemed to be worth describing and figuring as, to my knowedge, nothing like it has been seen in the genus Aphonogaster nor, indeed, in any 

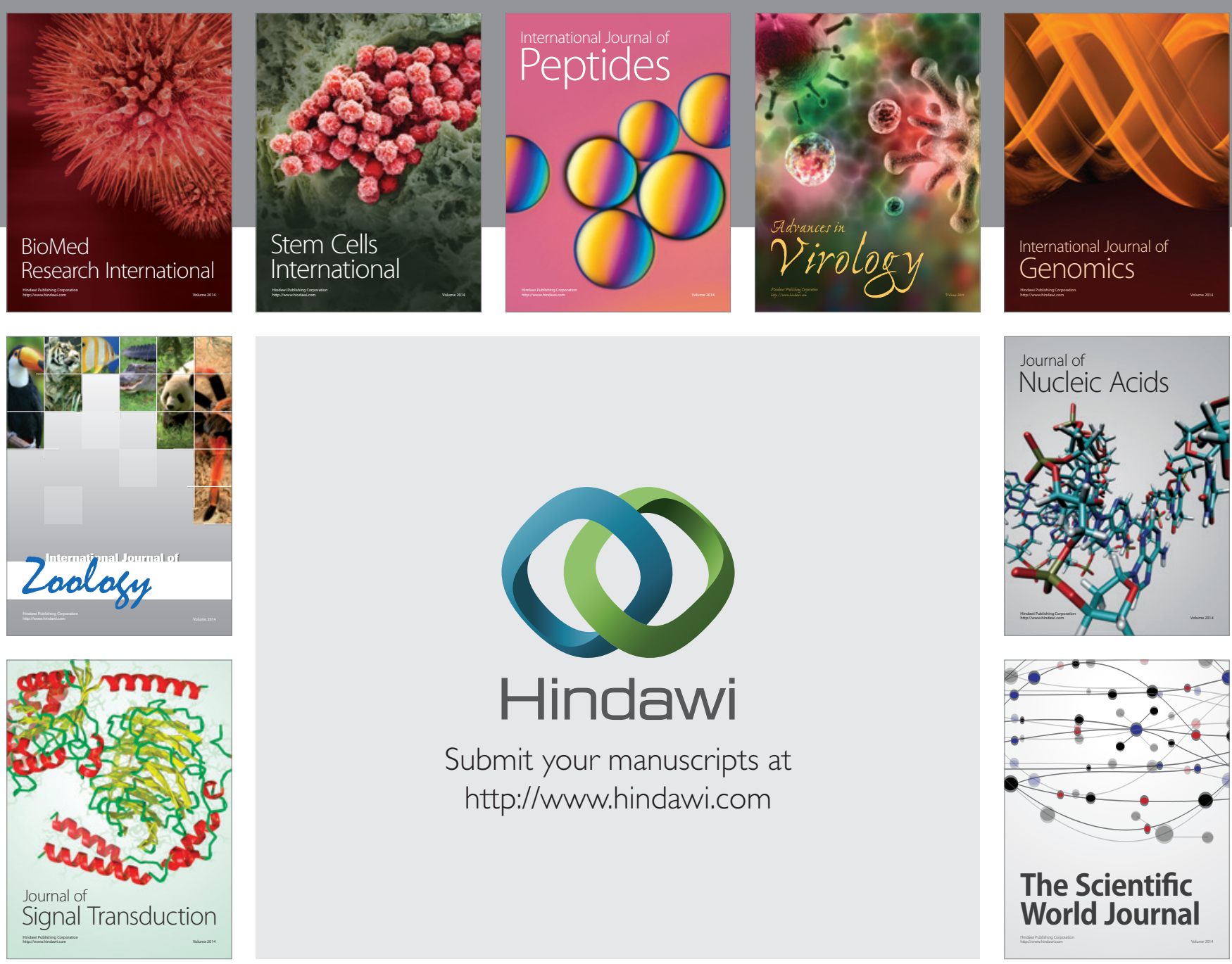

Submit your manuscripts at

http://www.hindawi.com
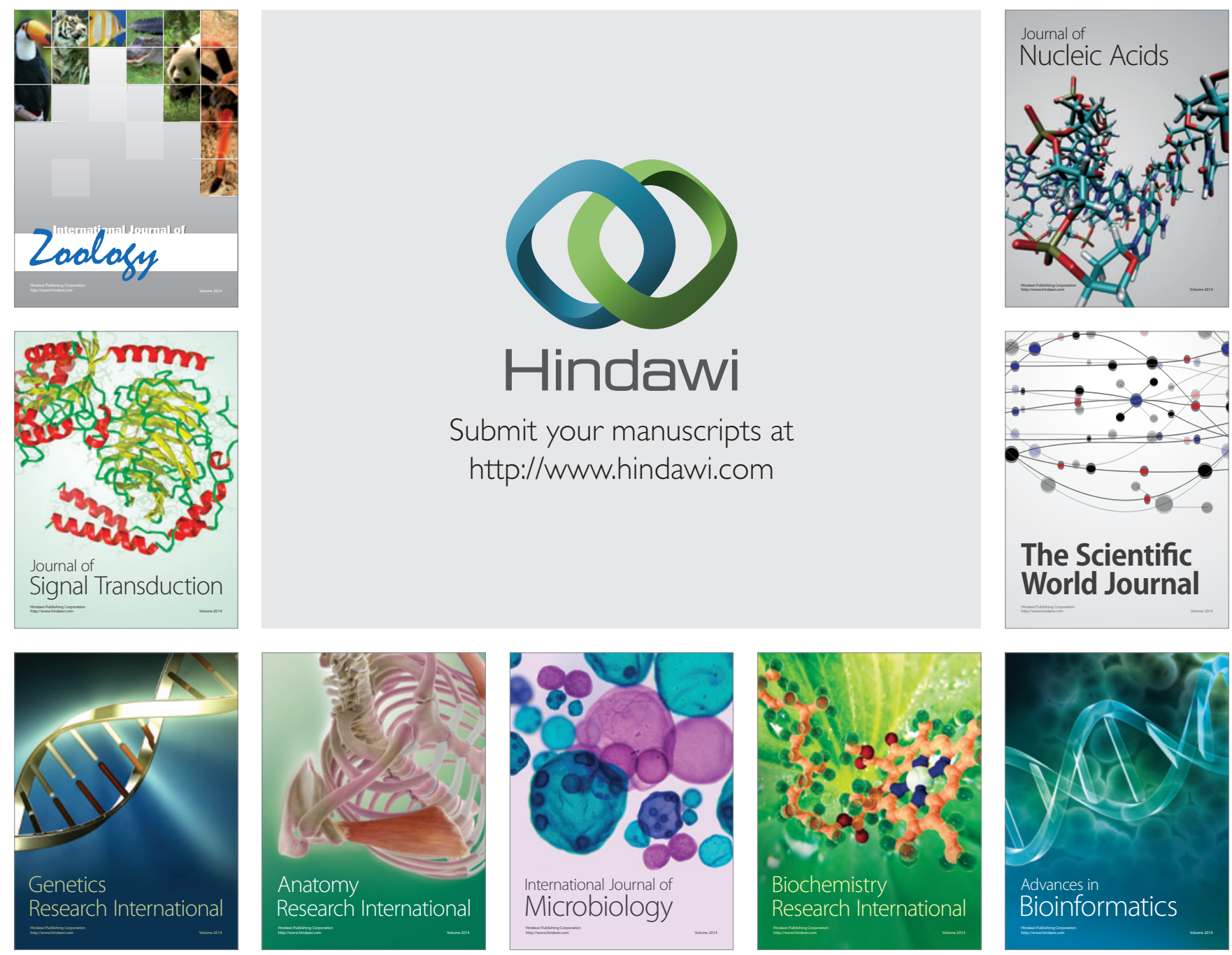

The Scientific World Journal
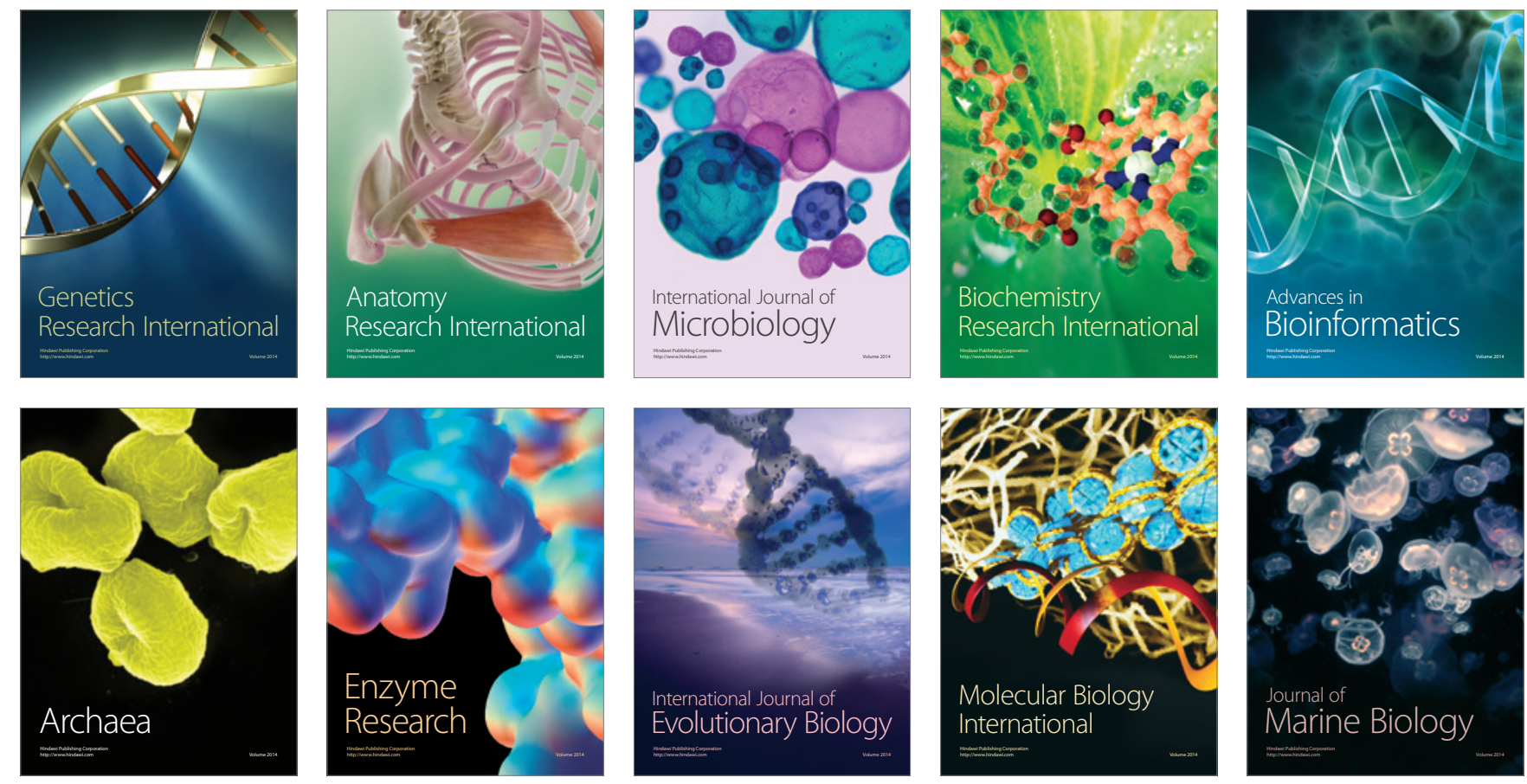